\title{
Clinical and translational research teams as a tool to improve global health
}

\author{
Estela S. Estapé*
}

President \& Founder, Estela S. Estape \& Associates Inc, USA

Across the globe, scientific, academic and health leaders are moving forward the concept of integration with the focus on increasing the effectiveness and efficiency of processes, especially those related to our health and well-being [1-3]. These efforts can have different names for its science, such as Health Disparities, Integrative Medicine, Implementation Science or Regulatory Science [4-7]. Although the depictions depend on each perspective and position, in service and research all lead to learning the skills of multiple disciplines working together toward a common goal. For example, advancements in pharmacogenomics research and genotyping technology have allowed the integration of genetic information with clinical data to improve the safety and effectiveness of medication therapy. Nevertheless, the implementation of pharmacogenomics (PGx) into clinical practice requires building a strong interdisciplinary team, consisting of stakeholders, such as: PGx service leader, physician, clinicians, laboratory specialists, and educators [8].

The success of building a research agenda to slowly but steadily eliminate health disparities in the world is, to my opinion, dependent on the diversity of its stakeholders and the way they communicate. How diverse are the clinical and translational research teams in their composition, roles and responsibilities, and how effective and efficient is their communication are essential elements to consider for success.

To attain these goals, it requires the development of skills and competencies needed to lead a successful multidisciplinary research team where everyone knows enough to be considered a leader [9]. From a very simple view point, a couple is the minimum of persons that you can have in any team. Anyone that has been in a personal relationship knows that to be successful, the partnership requires effort, commitment, optimism and patience. For a relationship to last over the enchantment period, including a research translational team, it requires at least the following five properties inherent to each of the participants and independent of the environment:

1. Fast, effective and efficient communication skills

2. Sharing of at least a goal in life

3. Similar values and respect for each other differences

4. Similar preferences in the things they do for enjoyment in life

5. Patience, persistence and perspicacity

In most relationships, there is a constant with change: the one who enters a new relationship is always enthusiastic, optimistic and full of energy to make changes, they are eager to achieve something important or make it work. The one that is leaving a relationship , when they entered for the first time, they too were feeling the same way and now, they are leaving with experience and ready to start again. I think this concept also applies to change in science: we should use the past experiences and knowledge to lead the creation of a new future. Consonant with this change and innovation, there is a trend to reorganize and transform current research agendas to:

- Address new areas of scientific and health priorities

- Respond to the need to maximize resources and increase productivity

- Have a stronger and faster impact in health and health care

- Achieve health equity and eliminate health disparities.

I agree and I think it's healthy, that new leaders seek input for transformational change from stakeholders and the general public for ways to contribute and improve success in eliminating health disparities for the next decade. Nevertheless, I ask myself what transformational change means for each of us. I really don't like too much the use of this term and if used, it should be very clear and transparent in its meaning. If the goal to set a transformational agenda means taking a visionary position that inspires people to follow and leads to positive changes in those who follow, I agree with transformational change. Since external funding is what sets the pathway for research priorities in academic institutions and scientific organizations, it's important for any successful transformational change to fulfill the following criteria:

(1) Define a vision to guide the development of the new research discipline for at least the next decade

(2) Identify key research areas that should be given high priority

In my opinion, a pathway to advance integrative medical fields (such as biochemistry and molecular and cell biology with regenerative medicine and pharmacology/toxicology) can be achieved using key research areas that are not specific disease oriented. Diseases can be used as proof of concept. Integration of strategies such as risk factors with biomarkers, behavioral with environmental, methodology with technology, information, dissemination and data bases can help advance the research integrative agenda [10].

Integration, together with a knowledgeable and diverse

Correspondence to: Estela S. Estapé, MT, PhD, FASAHP, DHL, Retired Professor, Graduate Dept., School of Health Professions, Former PI \& Director, Clinical and Translational Research Education and Career Development Programs; Former PI \& Director, Hispanics in Research Capabilty (HiREC) Endowment Program, Medical Sciences Campus, UPR, USA, Tel: 787- 414-0523; E-mail: estela.estape@upr.edu; estelaestape@gmail.com

Received: June 24, 2016; Accepted: July 05, 2016; Published: July 09, 2016 
conformation of translational teams, can lead to be more effective and efficient in working together to reach health equity. Thus, in my experience working with multidisciplinary teams, I have found that the following criteria are essential when setting a successful research agenda:

- Goals, objectives and measures of outcomes for determining success must be clearly established from the beginning

- There can be no space for confusion, leadership roles must be clear ( who is/are going to make the final decisions and take the blame for failure or share the success)

- Participants voices must be heard, their opinions analyzed and when a decision is made by the leaders, decisions must be reasonable and understandable to everyone, so the team feels united and working together toward reaching a goal

- If someone feels left out, the leaders have to immediately work it out. Sentiments that are left to cure for themselves only get worse with time.

If making it a success between only two people is a challenge, imagine the challenges when you need to create a multidisciplinary, multi-institutional, multicultural clinical and translational research team. Not easy, but it can be done if one starts with the correct attitude and open mind from the beginning. Thus, from clinical and translational research to implementation and regulatory sciences, the key factor is the integration of the knowledge that already exists with innovative concepts and an effective communication among the team members. The central goal of integration is to advance and fulfill the quest to provide insight on breakthrough discoveries in basic and clinical research to health applications and to forge new links between physicians, clinicians, scientists and stakeholders.

\section{Acknowledgement}

This work was supported by the National Institute on Minority Health and Health Disparities of the National Institutes of Health under Award Numbers U54MD007587, S21MD001830 and R25MD007607. Its contents are solely the responsibility of the author and do not necessarily represent the official view of NIH.

\section{References}

1. Dougherty D, Conway PH (2008) The " 3 T's" Road map to transform the US Health Care. JAMA 299: 2319-2321. [Crossref]

2. Selker HP (2010) Beyond translational research from T1 to T4: beyond "separate but equal" to integration (Ti). Clin Transl Sci 3: 270-271. [Crossref]

3. Estape ES (2016) Integration to advance translation. Int J Pathol Clin Res 2: 1-2.

4. Estape E, Soto de Laurido LE, Shaheen M, Quarshie A, Frontera W, et al. (2012) A Multi institutional, Multidisciplinary Model for Developing and Teaching Translational Research in Health Disparities. Clin Transl Sci 5: 434-438. [Crossref]

5. Maizes V, Horwitz R, Lebensohn P, McClafferty H, Dalen J, et al. (2015) The evolution of integrative medical education: the influence of the University of Arizona Center for Integrative Medicine. J Integr Med 13: 356-362.

6. Proctor E, Luke D, Calhoun A, McMillen C, Brownson R, et al . (2015) Sustainability of evidence-based healthcare: research agenda, methodological advances, and infrastructure support. Implementation Science 10: 1-13. [Crossref]

7. Altman RB, Prabhu S, Sidow A, Zook JM, Goldfeder R, Litwack D, Ashley E et al. (2016) Regulatory Science: A research roadmap for next-generation sequencing informatics. Science Translational Medicine 8: 1-4. [Crossref]

8. Arwood MJ, Chumnumwat S, Cavallari LH , Nutescu EA, Duarte JD (2016) Implementing Pharmacogenomics at Your Institution: Establishment and Overcoming Implementation Challenges. Clin Transl Sci: 1-14. [Crossref]

9. Estape E, Mays MH, Harrigan R, Mayberry R (2014) Incorporating translational research with clinical research to increase effectiveness in healthcare for better health. Clin Transl Med 3: 1-7. [Crossref]

10. Estape ES, Mays MH, Sternke EA (2016) Translation in Data Mining to Advance Personalized Medicine for Health Equity. Intell Inf Manag 8: 9-16. [Crossref]

Copyright: (C2016 Estapé ES. This is an open-access article distributed under the terms of the Creative Commons Attribution License, which permits unrestricted use, distribution, and reproduction in any medium, provided the original author and source are credited. 